\title{
A New Approach to Estimate from Monitored Demand Data the Limit of the Coverage of Electricity Demand through Photovoltaics in Large Electricity Grids
}

\author{
Francisco Baena ${ }^{1} * \mathbb{D}$, Francisco José Muñoz-Rodriguez ${ }^{2} \mathbb{D}$, Pedro Gómez Vidal ${ }^{2}$ and \\ Gabino Almonacid ${ }^{2}$ \\ 1 Department of Electronic and Automatic Engineering, University of Jaén, Campus Lagunillas, \\ 23071 Jaén, Spain \\ 2 Centro de Estudios Avanzados en Energía y Medio Ambiente CEAEMA, Universidad de Jaén, \\ 23071 Jaén, Spain; fjmunoz@ujaen.es (F.J.M.-R.); pvidal@ujaen.es (P.G.V.); galmona@ujaen.es (G.A.) \\ * Correspondence: fbaena@ujaen.es
}

Received: 8 June 2020; Accepted: 1 August 2020; Published: 6 August 2020

\begin{abstract}
In a traditional large electricity grid without storage, there is a limit to the maximum photovoltaic energy that can be consumed as the demand and generation may not match, either in magnitude or in time. This paper aims to provide a new method to estimate the limit of the coverage of electricity demand by photovoltaics in large electricity grids. This new method eliminates the random and the periodic variability over time as it is based either on the load duration curve for demand and the output duration curve for PV generation. We will assume there is no energy storage or inter-network exchanges. Moreover, conditions for the best scenario for photovoltaics are provided in order to estimate the upper limit: photovoltaic overgeneration is not considered and a complete system flexibility is assumed. The knowledge of this limit will manage to provide not only a reference for the planning of the energy sector but also to analyze the viability of the integration of future photovoltaic projects in the electrical system. In order to illustrate the method, several large electricity grids have been analysed in order to determine the aforementioned limit. Values between $19.3 \%$ and $29.9 \%$ have been obtained.
\end{abstract}

Keywords: coverage electricity demand; matching demand-photovoltaic; photovoltaics; renewable integration; demand-side; large electricity grid

\section{Introduction}

\subsection{Maximum Coverage of the Demand by Photovoltaics. Definition}

Photovoltaic energy is one of the generation sources known as variable energy resources (VERs) [1,2]. The main drawback of these energy sources is that they cannot completely match the demand curve. From a balancing perspective, the intermittent nature of these renewable energy sources are creating challenges in the electricity sector that previously were not of concern [3]. Moreover, there may be shortcomings with the availability and surplus of electricity depending on the irradiance and demand at a given time. Likewise, this availability is determined by the intrinsic intermittence of the solar resource: the periodic variability due to the variation throughout the year of the relative positions between the Earth and the Sun, and the random variability introduced by the atmosphere, mainly due to clouds and the variable activity of the Sun in much lower levels [4].

The daily output power curve of a photovoltaic (PV) power generation plant, in the absence of storage, follows the incident solar radiation. In this way, it provides, on a clear day, a maximum on 
solar noon and canceling at dawn. Since electricity cannot be stored on a large scale with simple and/or cost-competitive technologies, the generation of electrical power must occur at the same time this power is consumed. This implies that the electrical system, as a whole, has to be always ready to supply the electricity that is being demanded [5].

Furthermore, the demand for electricity in large electricity grids, with millions of consumers, is characterized by its daily load curve which remains above zero throughout the day with a minimum during the dawn and one or more peaks during the day and/or at first hours of the night. The behavior of this load curve generally depends on the climatology and the uses and customs of the population.

Both curves, PV generation and demand, cannot completely match as each one depends on different factors. Furthermore, the matching between these two curves has also the added difficulty that they both change independently throughout the year. Therefore, the matching between them, conditioned by the shape and magnitude of each curve, determines the amount of photovoltaic power that can be injected into the power grids and be absorbed by the demand ( $\left.\mathrm{E}_{\text {matchDPV }}\right)$. In this way, it can be expressed as [6]:

$$
\mathrm{E}_{\text {matchDPV }}=\mathrm{E}_{\mathrm{Dem}} \cdot \mathrm{C}_{\mathrm{T}} \cdot \mathrm{C}_{\mathrm{Mag}}
$$

where $C_{T}$ is a coefficient due to the matching between the PV generation time and the time in which demand occurs. This coefficient is given by the relation between the maximum time of PV generation over a period of time and the total duration of demand in the same period (its maximum value is 1 ). For photovoltaics without storage in large conventional networks it will be around $0.5 . \mathrm{C}_{\mathrm{Mag}}$ is a coefficient that reflects the matching between the magnitudes of the PV generation and demand. It is obtained by the average photovoltaic power harvested during the generation time divided by the average demand power during the same interval. Its maximum value is 1 , although without PV overcapacity this coefficient will be significantly lower than 1 .

Without going into other considerations and only taking into account the behavior of the demand and photovoltaic generation curves, in a traditional power grid, it can be said that the matching between them will never be $100 \%$, without considering any kind of electricity storage. This fact will imply that there will be a limit on the maximum coverage of the demand by photovoltaics $\left(\mathrm{CD}_{\mathrm{PVmax}}\right)$. This parameter, or average penetration, is the proportion of electric energy which is being supplied from photovoltaic plants. The coverage of demand is defined by the following equation [5]:

$$
\mathrm{CD}_{\mathrm{PV} \max }=\frac{\mathrm{E}_{\text {matchDPV }} \text { max }}{\mathrm{E}_{\text {Dem }}}
$$

The limit of the coverage of electricity demand for a given electricity generation technology is an indicator of the potential of this technology. Therefore, the limit of the $\mathrm{CD}_{\mathrm{PV}}\left(\mathrm{CD}_{\mathrm{PV} m a x}\right)$ is an indicator of the ability of photovoltaic solar energy to cover the electricity demand for a given grid. Solar PV has a limitation when considering the amount of energy that can be absorbed by a large conventional electrical grid. This is due to the matching between the demand curve and the photovoltaic generation curves. Currently, in most networks, the installed photovoltaic power is far from reaching this limit. However, the accumulated PV power is continuously increasing and getting closer to this limit. The $\mathrm{CD}_{\mathrm{PV}}$ limit may provide, given the aforementioned boundary conditions, the maximum photovoltaic power that a given grid can absorb. In this sense, this limit can be very useful in energy planning of large electricity grids as it provides certainty to future projects of photovoltaic installations about the capacity of the demand to absorb the photovoltaic energy that can be generated.

It must be highlighted that this limit refers only to the matching between electricity demand and PV generation, regardless of the limits imposed by the energy resource [7], the necessary material for photovoltaic installations [8,9], transport in the grid [10] or other restrictions [11]. Therefore, in order to estimate this limit of the $\mathrm{CD}_{\mathrm{PV}}$, it is necessary to study both the behavior of the electricity demand for a specific network and the one corresponding to the PV generation that is injected into it. 
Currently, although the level of $\mathrm{CD}_{\mathrm{PV}}$ is low, there are very significant growth estimations. In the countries with the highest coverage it was slightly higher than $8 \%$ while in EU and the world as an average it reached 5\% and 3\%, respectively, in 2019 [12]. However, this coverage will increase significantly as an annual growth of the new photovoltaic power installed of $9 \%$ is expected for the period 2020-2024 [13]. If this growth is kept in the next decades, there will be many countries with a considerable increase in $\mathrm{CD}_{\mathrm{PV}}$ where PVs may become one of the main sources of electricity generation Nowadays, in most networks, the installed photovoltaic power is still far from reaching $\mathrm{CD}_{\mathrm{PVmax}}$. However, the accumulated PV power is continuously increasing and getting closer to this limit. The $\mathrm{CD}_{\mathrm{PV}}$ limit may provide, given the aforementioned boundary conditions, the maximum photovoltaic power that a given network can absorb without storage and inter-network exchanges.

\subsection{Methods to Estimate the Upper Limit of the CDPV in a Large Electricity Grid. State of the Art}

Several researchers have explored the integration of photovoltaic power generation into conventional power grids, although only a few have tried to estimate the technical limit of the penetration of PV with respect to the demand. In the different published papers on this subject it is observed that the most generalized method to determine the limit of the $\mathrm{CD}_{\mathrm{PV}}$ is based on comparing the electricity demand data for a given network and for a particular year with the PV generation data obtained indirectly from the solar radiation data in the network area for the same year [14-17].

In all these papers, the PV energy injected into the network is estimated by computer simulation, assuming determined characteristics of the PV system connected to the network, such as the type of tracking, the overall performance of PV installations, etc. In this way, the electricity demand curve for the whole year is compared with the simulated annual PV generation curve for the same year. Moreover, the value of the instantaneous PV power is scaled for the whole year to different values of the demand power (either referred to the maximum annual power or annual average power), considering whether or not there is overcapacity of PV generation, i.e., if the instantaneous PV power exceeds the demand at a given time and in what magnitude it exceeds. Also, it is considered whether there is energy storage to absorb this PV generation excess, exchanges between networks or if it is directly lost. All this leads to different scenarios that estimate different limits of the $C D_{P V}$ that prevent any kind of comparison. The block diagram of Figure 1 succinctly shows the aforementioned methods.

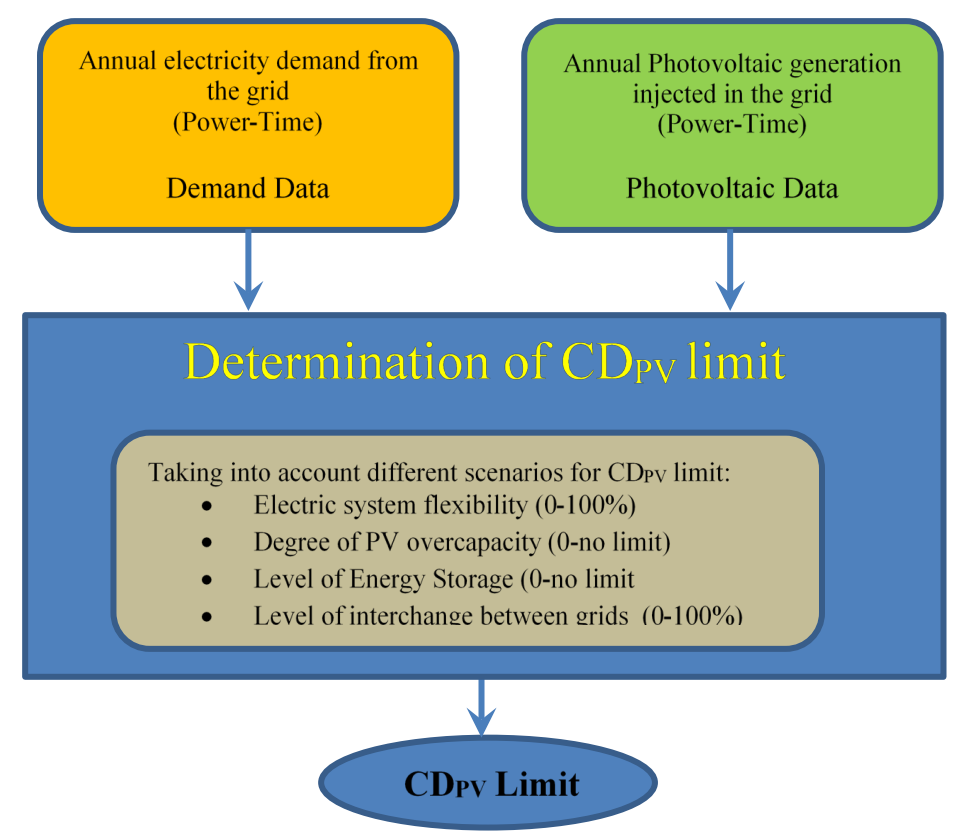

Figure 1. Methods used in the literature to estimate the limit of the coverage of electricity demand by means of PV's. As it can be seen, different scenarios can be considered. 
This method, which is used in the different referenced papers, estimates the limit of $\mathrm{CD}_{\mathrm{PV}}$ through Equation (3) [5]:

$$
\mathrm{CD}_{\mathrm{PV}}=\frac{\mathrm{E}_{\mathrm{PV}}}{\mathrm{E}_{\mathrm{Dem}}}=\frac{\sum_{\mathrm{n}=1}^{365} \sum_{\mathrm{i}=1}^{24} \mathrm{P}_{\mathrm{n}, \mathrm{i}}^{\mathrm{PV}} \Delta \mathrm{t}}{\sum_{\mathrm{n}=1}^{365} \sum_{\mathrm{i}=1}^{24} \mathrm{P}_{\mathrm{n}, \mathrm{i}}^{\mathrm{Dem}} \Delta \mathrm{t}}
$$

where $\mathrm{P}^{\mathrm{PV}}{ }_{\text {ni }}$ y $\mathrm{P}^{\mathrm{Dem}}{ }_{\text {ni }}$ define the average powers of each sample $i$ taken at a given recording interval $\Delta t$, for each $\mathrm{n}$ day of the year, for the photovoltaic generation and the demand, respectively.

This equation is valid for the PV power as long as the latter is equal to or less than the demand power. In this sense, the excess of PV generation or PV overgeneration that takes place is not considered. The PV overgeneration can be defined as the generation of PV electricity above the one needed to meet the demand. This can be lost or stored. Whereas, PV overcapacity is defined as the availability of installed PV power above the need for PV generation. The latter may be conditioned by a limitation in the output power.

The aforementioned papers provide a range of values for the limit of the coverage of the demand that depends mainly on the flexibility of the network, the degree of PV overcapacity, the level of storage and, in some cases, the cost of kWh expressed as a function of the previous variables. A limit of the $\mathrm{CD}_{\mathrm{PV}}$ is given for an extreme scenario of $100 \%$ flexibility, without storage and without PV over-generation. All of them consider a conventional demand profile (that of for the considered year) for the analysed networks [14,16-18]. The data corresponding to the networks of the state of Texas are from the year 2000, in the state of New York they are from the year 2005, in the metropolitan area of Zurich they are from October 2007 to September 2008 and the network of Switzerland is from the year 2005. The limit obtained in these papers is $22 \%$ (considering a $65 \%$ flexibility for the electricity grid regarding photovoltaics), $14.83 \%, 17 \%$ (with a $1 \%$ of PV overcapacity) and $24 \%$, respectively. The last case is not comparable to the other three works, since, in addition to the comments at the beginning of this section, it considers a flexibility of 75\% and a single ideal day of PV generation, on 20 June 2007, which is extrapolated for the whole year.

The values proposed by these authors are not absolute limits of the $\mathrm{CD}_{\mathrm{PV}}$, even in this extreme scenario, since in all cases they are determined for a specific year and a specific network, both for PV generation and demand, which do not guarantee that in that year and in that network the best conditions are given to obtain the maximum matching between the PV generation and the electricity demand. In addition, none of these studies are carried out in different years or networks in order to make a comparison of results.

Furthermore, the main drawback is that the aforementioned method depends strongly on the variation of both demand and PV generation over time. For example, if the maximum annual power of PV generation coincides on Sunday, it will provide a different limit if it falls on Wednesday. Moreover, different limits will be obtained if this maximum value coincides with a heat wave or it takes place on an average temperature day.

This paper aims to present a new method to estimate the maximum limit in the coverage of the demand by photovoltaics imposed by the coupling between the demand and the photovoltaic generation in a large and classic electricity grid. The knowledge of this limit may be of special interest for the energy planning of a territory and for the management of the electric network operators. The method here developed is based on the load duration curve (LDC) for demand and the output duration curve $\left(\mathrm{ODC}_{\mathrm{PV}}\right)$ for $\mathrm{PV}$ generation. This new method has the advantage of eliminating the random and the periodic variability over time of the instantaneous PV power and, to a lesser extent, of the electricity demand. This fact will be shown in the next sections. In this sense, it makes possible to estimate the upper limit in the $\mathrm{CD}_{\mathrm{PV}}$ in a simple and intuitive way, as the aforementioned curves are stable for a given network and for different years [6]. It should be noted that this limit is estimated considering a determined scenario: without electrical storage, without photovoltaic overgeneration, i.e., all the photovoltaic electricity generated must be absorbed by the demand considering total flexibility of the electrical system, and using the conventional $\mathrm{ODC}_{\mathrm{PV}}$ and $\mathrm{LDC}$ profiles of each network. 
In order to achieve the aforementioned objective, the paper will be structured as follows. In Section 2 the new method based on LDC and ODC ${ }_{P V}$ curves is developed. Next, in Section 3 the results obtained when applying this method to several large electricity grids are presented. Finally, the most relevant conclusions are drawn in Section 4.

\section{Materials and Methods}

\subsection{Estimation of the Upper Limit of the $C D_{P V}$ in a Large Electricity Grid: Proposed Method}

A new method for the estimation of the upper limit of the CDPV in large electricity grids with conventional demand profiles will be developed, Figure 2. The latter is based on the use of the load duration curve (LDC) for demand and the output duration curve for PV generation (ODC $\mathrm{PV}_{\text {). }}$.

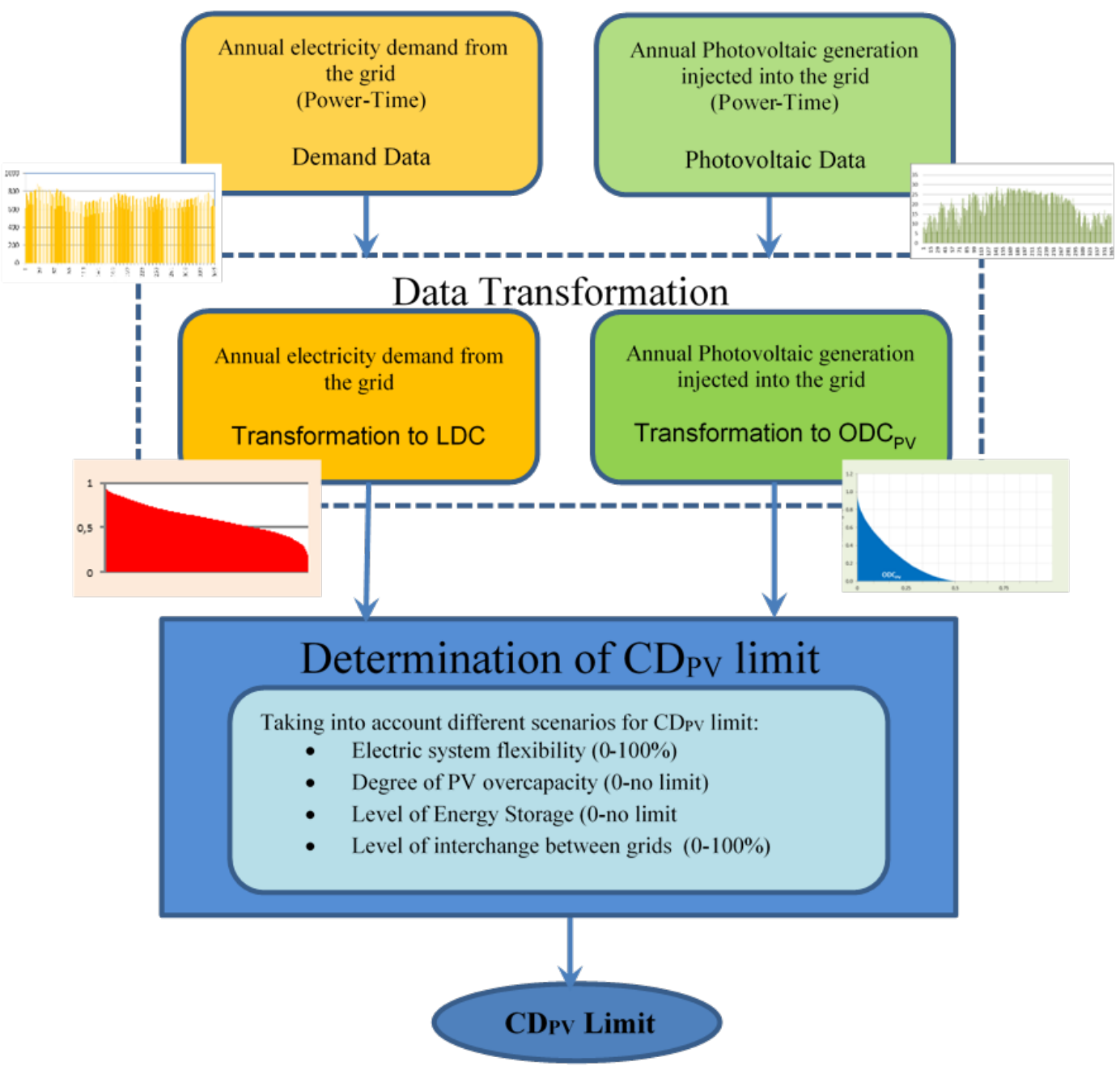

Figure 2. Proposed method for the estimation of $\mathrm{CD}_{\mathrm{PV}}$ in a large electricity grids.

These curves provide a transformation of the data used in the aforementioned methods. In the latter, the power is plotted as a function of the time. However, both LDC or ODC $\mathrm{PV}$ are curves rearranged hour-by-hour in chronological order based on power magnitude [19], i.e., they show how long a certain power is maintained in a decreasing monotone way. These curves can be daily, weekly, monthly or annual. In this paper, only annual curves will be considered ( $8760 \mathrm{~h} /$ year).

In this way, this transformation eliminates the temporal variability of the data and makes it possible to obtain the limit of the coverage of the demand avoiding the noise that incorporates this 
variability, noise that for this limit is indifferent or, at least, of little relevance. However, this noise makes it difficult to obtain the limit of $\mathrm{CD}_{\mathrm{PV}}$ when considering other methods.

These curves have the advantage of maintaining their shape for different years [20]. The ODC ${ }_{P V}$ depends on the type of solar tracking of the PV plants, the dispersion between plants of the same large-scale PV system, the PV generation overcapacity and the annual radiation profile incident on the photovoltaic field. Meanwhile, the LDC of a large power grid depends mainly on the electricity consumption habits of the network population and the climatology. Radiation and climatology undergo variations if observed at a small scale (e.g., a day, a week or a month), but they are stable if observed at a larger scale of time such as a year. The other variables remain stable over the years.

Furthermore, both curves eliminate random and periodic variability of power with respect to time, since they do not represent the power with respect to chronological time but with respect to the number of hours that this power is maintained at a certain level, obtaining a decreasing monotonous representation [21,22]. This issue, together with a determined scenario, manages to develop a simple and effective method for the estimation of the limit the PV's can reach in the coverage of the demand according to the profiles of the LDC and the ODC $\mathrm{PV}$.

In order to estimate the upper limit of the $\mathrm{CD}_{\mathrm{PV}}$, it will be defined the best scenario for PV's will be defined: the annual demand profile of a large electricity grid will be considered in its normalized LDC form stable over the years and with 100\% electrical system flexibility to give maximum priority to PV's (i.e., this would imply subordinating all other sources participants in the grid energy mix to the PV's). Moreover, neither excess of PV generation nor any kind of energy storage will be considered. To complete this scenario, the following conditions are defined to obtain the maximum matching between the demand and the PV generation:

(1) The maximum annual output peak power of the PV generation matches, in magnitude and in time, with the maximum annual power of the demand.

(2) For every day of the year, the instantaneous demand power will always be equal to or greater than the instantaneous power of the PV generation.

These conditions are clearly theoretical and are only of interest in providing the best scenario, since any other conditions will determine a lower $\mathrm{CD}_{\mathrm{PV}}$ limit. However, it must be said that the first condition can be easily achieved, or at least, got close to it, in electricity grids of warm zones, where the maximum annual demand power of demand is reached in summer and near noon. An example of this is case of the ERCOT network in Texas [14].

With respect to the second condition, it is necessary to emphasize the sharp decline in the demand that takes place at weekends and during holidays. However, the monotonic decreasing PV generation curve $\left(\mathrm{ODC}_{\mathrm{PV}}\right)$ has two characteristics that facilitate compliance with this point. The first one is that its duration is around half the duration of the demand curve (LDC), while the second one is that the power decay slope is higher in the $\mathrm{ODC}_{\mathrm{PV}}$ than in the LDC. Moreover, it must be highlighted that this problem diminishes as we move away from the summer solstice.

Despite the two issues mentioned above, the sharp decrease in demand at weekends and during holidays would mean that in these days the second condition set to achieve the maximum $C D_{P V}$ is not met. However, in most of the networks studied, the PV generation decreases in a proportion equal to or greater than the demand in a number of days similar to that of weekends and holidays (about 110 days), both circumstances do not coincide in time. In order to take into account this second condition it can be assumed that the weather conditions throughout the year reduce the PV generation at weekends and during public holidays without changing the annual balance. This implies assuming a hypothetical translation of the PV generation in time, without modifying its magnitude and therefore the $\mathrm{ODC}_{\mathrm{PV}}$, as shown in Figure 3. 


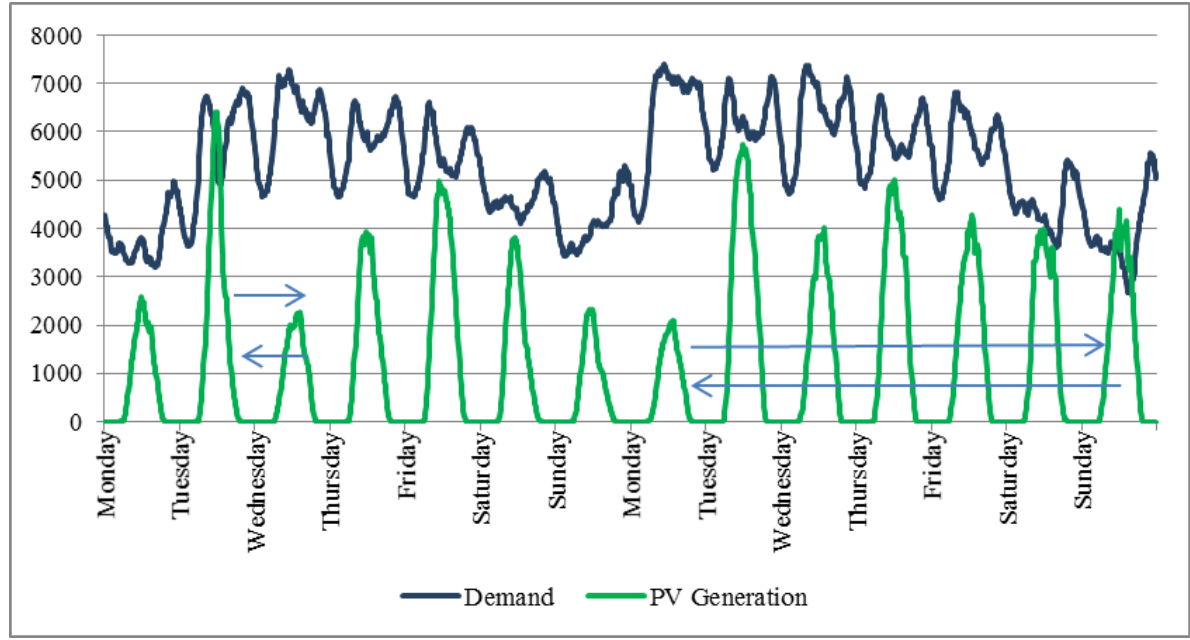

Figure 3. Theoretical displacement of the PV generation curves in order to achieve the best scenario (2nd condition) for CD PVMAX. Real data corresponding to Transnet network (9-22 April 2012).

It must be highlighted that in these types of curves (LDC and $\mathrm{ODC}_{\mathrm{PV}}$ ) the time axis is not ordered following the arrow of time (i.e., past towards the future) but attending to the value of the power of each temporary sample. In these curves, the average hourly power is classified from its maximum value to its minimum value, regardless the time in which it occurred [23].

Figure 4 shows an example of LDC, where the area under the curve represents the energy consumed if both axes are in real magnitudes ( $\mathrm{W}$ and $\mathrm{h})$. In this way, for the demand energy $\left(\mathrm{E}_{\mathrm{Dem}}\right)$, the area under the LDC may be given as:

$$
E_{D e m}=\sum_{i=1}^{L} P_{D i} \Delta t
$$

where $L$ is the number of annual hours, $P_{D i}$ is the average hourly power demanded and $\Delta t$ is the recording interval $(1 \mathrm{~h})$.

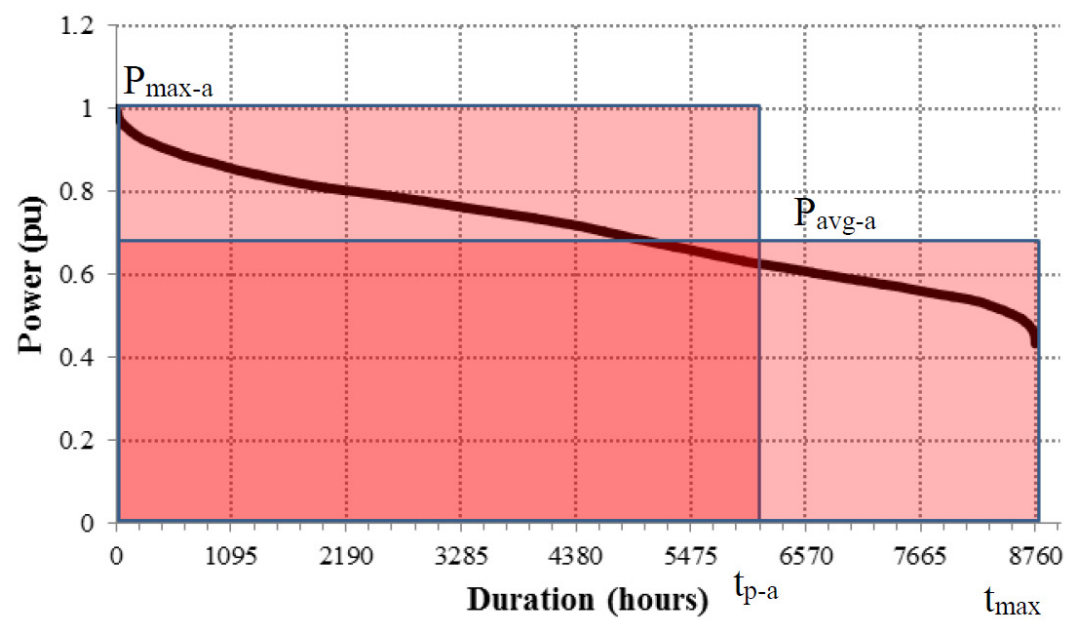

Figure 4. LDC and equivalent rectangular areas.

In contrast, when the power axis is represented in a normalized form, referred to the maximum annual power consumed $\left(P_{\max -\mathrm{a}}\right)$, the area under the normalized curve represents the total number of hours at the maximum annual power $\left(t_{\mathrm{p}-\mathrm{a}}\right)$ that would have been needed to match the energy demanded in the considered year. If both axes are normalized in parts per unit $(\mathrm{pu})$ the area under the curve has no dimensions and it will provide the annual load factor (LF) of the system. 
The area under the curve can be expressed as equivalent rectangular surfaces, as can be seen in Figure 4. This approach manages to obtain the value of the area as the product of the base by height. So that the annual electric energy demanded can be expressed by Equation (5), using either the maximum annual power together with $t_{\mathrm{p}-\mathrm{a}}$ or the average annual power $\left(\mathrm{P}_{\mathrm{avg}-\mathrm{a}}\right)$ and the maximum annual time $\left(t_{\max -a}\right)$ for demand.

$$
E_{\text {Dem }}=P_{\text {max }-a} \cdot t_{p-a}=P_{a v g-a} \cdot t_{m a x-a}
$$

Regarding PV generation, the area below the $\mathrm{ODC}_{\mathrm{PV}}$ curve, Figure 5, is given by Equation (6) which estimates the photovoltaic energy generated throughout the year:

$$
E_{P V}=\sum_{i=1}^{L} P_{G i} \Delta
$$

where $L$ is the number of annual hours, $P_{G i}$ corresponds to the average hourly power generated and $\Delta t$ is the time interval $(1 \mathrm{~h})$.

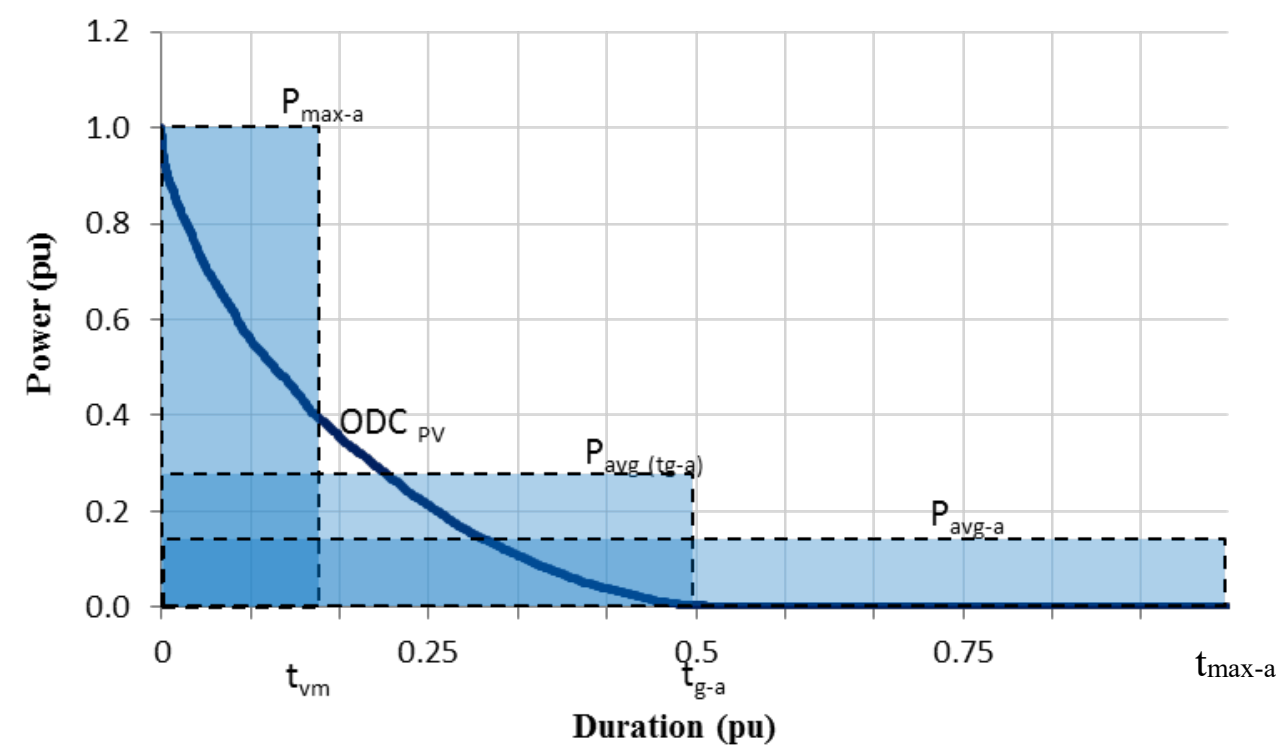

Figure 5. $\mathrm{ODC}_{\mathrm{PV}}$ and their equivalent rectangular areas.

When analysing the $\mathrm{ODC}_{\mathrm{PV}}$ curve, the following considerations should be taken into account, Figure 5.

- The range of the abscissa axis when considering power values is about half the one-year hours for PV systems without storage (4380 $\mathrm{h}$ in a non-leap year). This is because, without considering any kind of energy storage, a PV plant can generate electricity, on average, about 12 h every day of the year.

- $\quad \mathrm{ODC}_{\mathrm{PV}}$ is delimited by the following parameters: $\mathrm{P}_{\text {max-a }}$ (maximum annual hourly AC power generated) and $t_{g-a}$ (annual PV generation time). This last one represents the total number of hours per year that the PV plant has been supplying power to the grid and it is around half the annual maximum time.

- Two additional parameters can be defined on $\mathrm{ODC}_{\mathrm{PV}}$ : the average power of photovoltaic generation for the time $t_{g-a}, P_{a v g-a(t g-a)}$, and the average power, for the maximum annual time $\left(t_{\text {max-a }}=8760 \mathrm{~h}\right.$ for a non-leap year $)$, is given by $\mathrm{P}_{\text {avg-a }}$.

As was done with LDC, the same area under the $\mathrm{ODC}_{\mathrm{PV}}$ can be represented by equivalent rectangular areas using the previously defined parameters of power and time.

In this sense, the area under the $\mathrm{ODC}_{\mathrm{PV}}$, can be expressed in different magnitudes: 
- If the two axes are in real values (W-h) the area under the $\mathrm{ODC}_{\mathrm{PV}}$ represents the output energy of the PV system given in Wh/year.

- If the power axis is normalized with respect to the maximum annual power $(\mathrm{pu})$ and the time axis is maintained in real values $(\mathrm{h})$, the area under the $\mathrm{ODC}_{\mathrm{PV}}$ corresponds to the annual final yield given in hours/year, that is $t_{\mathrm{vm}}$. The latter can be defined as the number of equivalent annual hours operating at maximum annual AC power measured at the output of the system to generate the annual energy produced. This parameter, $t_{\mathrm{vm}}$, can be also defined as the ratio between the annual photovoltaic energy injected into the network $\left(E_{P V}\right)$ and Pmax-a, as the maximum effective aggregate power of the set of plants that constitute the PV system. It must be highlighted that $t_{\mathrm{vm}}$ do not correspond to the system final yield as the latter is calculated by dividing the net energy output of the entire system in AC (this value does match $\mathrm{E}_{\mathrm{PV}}$ ) per rated $\mathrm{kW}(\mathrm{DC})$ of installed power [24].

- If both axes are normalized (pu), the area under $\mathrm{ODC}_{\mathrm{PV}}$ has no dimensions and it will provide the dimensionless ratio of electrical PV energy output over a given period of time to the maximum possible electrical energy output over that period, i.e., the capacity factor (CF) of the PV system.

Therefore, these rectangular areas represent the $\mathrm{CF}$, the annual final yield (in large power grid) given in hours or the photovoltaic energy injected into the network, depending on whether the axes are defined in pu or in real values, respectively. In this sense, the output energy of the PV system can be expressed by the equation:

$$
E_{P V}=t_{v m} P_{\max -a}=t_{g-a} P_{a v g(t g-a)}=t_{\max -a} P_{a v g-a}
$$

Therefore, the theoretical limit that can be reached by the PV generation is determined by the relation between the PV energy injected into the grid and the energy demanded by the same network. Up to to this point, there are no changes to the method used in the cited literature [14,16,17]. However, as already mentioned, the new method here developed is based on the $\mathrm{ODC}_{\mathrm{PV}}$ and LDC curves since the area under them represents the corresponding energies of PV generation and demand, respectively. In this way, the coverage of the demand by solar photovoltaics, $\mathrm{CD}_{\mathrm{PV}}$, may be given by the following expression $[6,20]$ :

$$
C D_{P V}=\frac{L D C_{\text {area }} \cap O D C_{\text {PVarea }}}{L D C_{\text {area }}}
$$

where the numerator of Equation (8) represents the useful PV consumed energy due to demand. This ratio implies that if the whole area under the $\mathrm{ODC}_{\mathrm{PV}}$ curve is included in the area under the LDC, the limit of the $\mathrm{CD}_{\mathrm{PV}}$ can be expressed by Equation (9), if conditions 1 and 2 of the best scenario are fulfilled:

$$
O D C_{P V \text {-area }} \in L D C_{\text {area }} \Longrightarrow C D_{P V}=\frac{O D C_{P V \text {-area }}}{L D C_{\text {area }}}
$$

For LDC and $\mathrm{ODC}_{\mathrm{PV}}$ curves, these areas can be expressed as a function of their respective power summations as a function of time (Equations (4) and (6), respectively) or by means of equivalent rectangular areas (Equations (5) and (7)). These equivalent rectangular areas for demand and PV generation are shown in Figure 6 where the associated parameters for equivalent rectangular area are also given.

Using Equations (5) and (7) the limit of the $\mathrm{CD}_{\mathrm{PV}}$ can be estimated by the ratio of the different parameters associated with the equivalent rectangular areas, as given in the equation below:

$$
C D_{P V}=\frac{E_{P V}}{E_{D e m}}=\frac{t_{v m}}{t_{p-a}}=\frac{P_{a v g-a}^{P V}}{P_{a v g-a}^{D e m}}=\frac{t_{g-a} \cdot P_{a v g(t g-a)}^{P V}}{t_{\text {max }-a} \cdot P_{a v g-a}^{D e m}}
$$


Comparing the last term of Equation (10) with Equation (1), coefficients $C_{T}$ and $C_{\text {Mag }}$ may be obtained. Therefore, the $\mathrm{CD}_{\mathrm{PV}}$ may be expressed as the product of these two coefficients.

$$
\begin{gathered}
C_{T}=\frac{t_{g-a}}{t_{\max -a}} \\
C_{\mathrm{Mag}}=\frac{P_{a v g(t g-a)}^{P V}}{P_{a v g-a}^{\text {Dem }}} \\
C_{P V}=C_{T} \cdot C_{\mathrm{Mag}}
\end{gathered}
$$

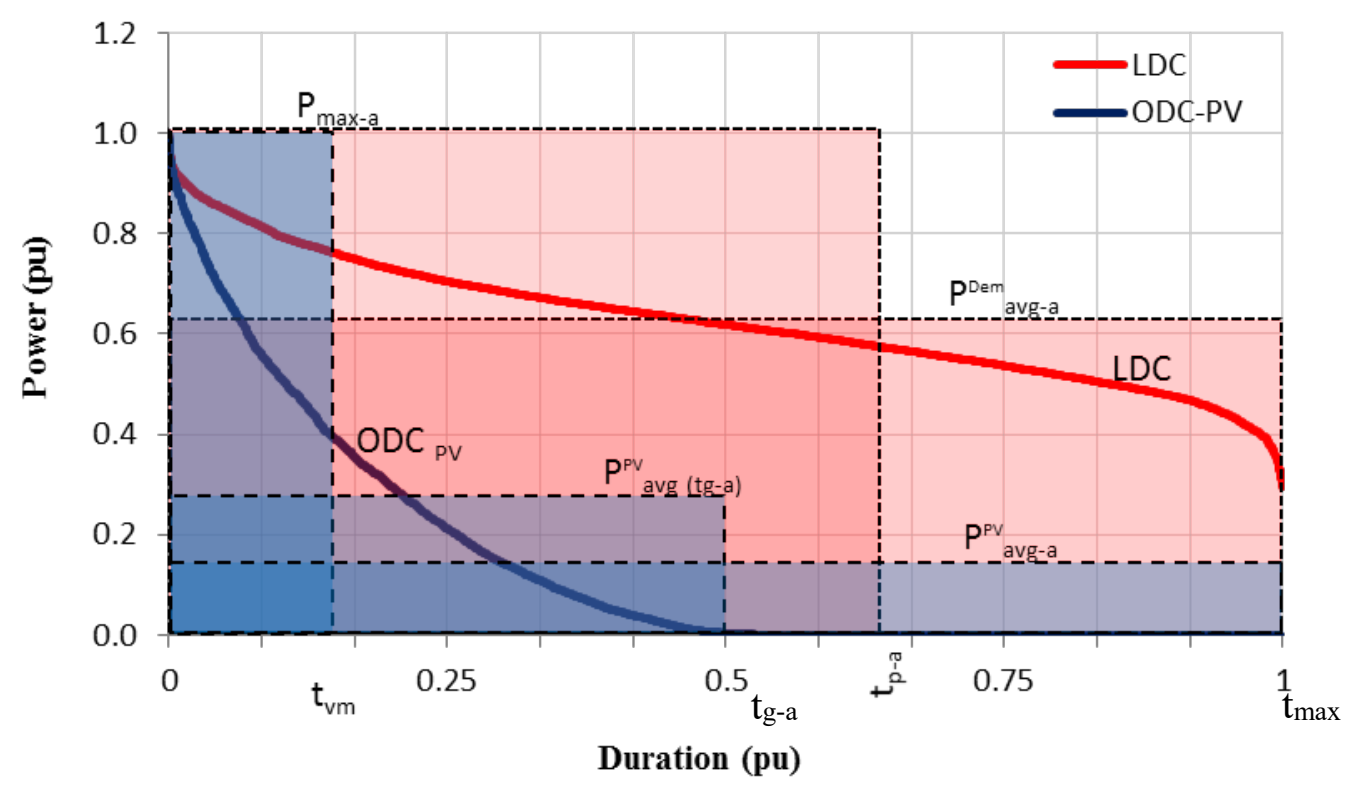

Figure 6. Equivalent rectangular areas for the PV generation (blue) and the demand (red).

Any of the relations shown in Equations (10) and (13) can be used to determine the $\mathrm{CD}_{\mathrm{PV}}$ limit. The choice of one or the other will depend only on the ease in obtaining the corresponding parameters.

As can be seen, the main advantage of this method is that it manages to obtain an upper limit in the coverage of the demand with PVs regardless both the grid and the year. This limit only depends on the profile of the LDC and $\mathrm{ODC}_{\mathrm{PV}}$ curves, which are stable for different years and very similar between grids of similar latitudes and similar consumption habits [25].

This maximum limit will be reached if the scenario set out at the beginning of this section is fulfilled. In the next section, and in order to illustrate the proposed method, the latter will be applied to several large scale electricity grids from different countries in order to determine the limit of the coverage of the demand by means of PVs.

\subsection{Data}

The developed method will be applied to several large scale electricity grids of different countries considering data of both photovoltaic and electricity demand for the same period of time: Amprion, Tennet, Transnet and 50 Hertz from Germany, Elia from Belgium and REE-Tenerife from Spain. Table 1 shows general data of each grid, the covered area and population. The electricity demand data of a given electricity grid are provided by their corresponding Transmission System Operators (TSO) websites of each electricity grid, both for photovoltaic generation [26-31] and for the demand [32-37]. TSOs must make these data public in accordance with Regulation (EU) No 543/2013 [38]. The data to be downloaded correspond to the average power, the recording interval and the time and date of each sample. 
Table 1. Analyzed electricity grids. General data.

\begin{tabular}{cccc}
\hline Electricity Grid & Country & Area $\left.\mathbf{( k m}^{\mathbf{2}}\right)$ & Population Attended $\mathbf{( 1 0}^{\mathbf{6}}$ Inhabitants) \\
\hline Amprion & Germany & 73,100 & 27 \\
Transnet & Germany & 34,600 & 11 \\
Tennet & Germany & 138,780 & 20 \\
50-Hertz & Germany & 109,360 & 18 \\
Elia & Belgium & 30,528 & 10 \\
REE-Tenerife & Spain & 2034 & 0.9 \\
\hline
\end{tabular}

As a necessary preliminary step, the data preprocessing should be highlighted in order to provide the appropriate format for the analysis.

The source data present recording intervals of 10,15,30 and $60 \mathrm{~min}$, depending on the TSO. In this way, the recording interval has been normalized to one hour. An interval of $60 \mathrm{~min}$ has been chosen because it is the least common multiple of all the available intervals. To transfer all the data from the different grids to this common sampling interval, the following equation has been used:

$$
P_{i}=\frac{1}{N} \sum_{\substack{j=24 \\ j=1 \\ i=1}}^{\substack{j=N \\ i j}} \text { para } N=\frac{60 \mathrm{~min}}{\Delta t}
$$

where $P_{i}$ : Average power in the normalized recording interval, $P_{i j}$ : average power in the original recording interval, $\Delta t$ : original recording interval given in minutes and $N$ : number of originals recording intervals for each normalized recording interval.

In addition, due to the significant difference in size between the different grids, it is also neccesary to normalize the peak power or anual maximun power as it varies from $8 \mathrm{MW}$ to $100 \mathrm{GW}$. In this sense, the power has been normalized in parts per unit (pu) [5] to the annual máximum power using the following expression:

$$
P_{i(p u)}=\frac{P_{i}}{P_{\max -a}}
$$

where $P_{i(p u)}$ : Normalized power in pu, $P_{i}$ : Average power in the normalized recording interval $(1 \mathrm{~h})$ and $P_{m a x} a$ : Annual maximun power.

Moreover, it should be noted that there are two issues regarding the source data that must be corrected:

- Incoherent data and lack of data: both the absence of data and incoherent data. Estimation techniques have been used such as the quantitative method of time series called "Trend projection" [39] in order to correct these anomalies.

- The time change: throughout the European Community [40] the official time will be advanced one hour on the last Sunday of March and will be delayed one hour on the last Sunday of October. In North America it is similar, one hour is advanced on the second Sunday of March and is delayed on the first Sunday of November.

Figures 7 and 8 shows annual data, once processed, provided by the TSO (German 50 Hertz), corresponding to photovoltaic generation and demand, respectively. 


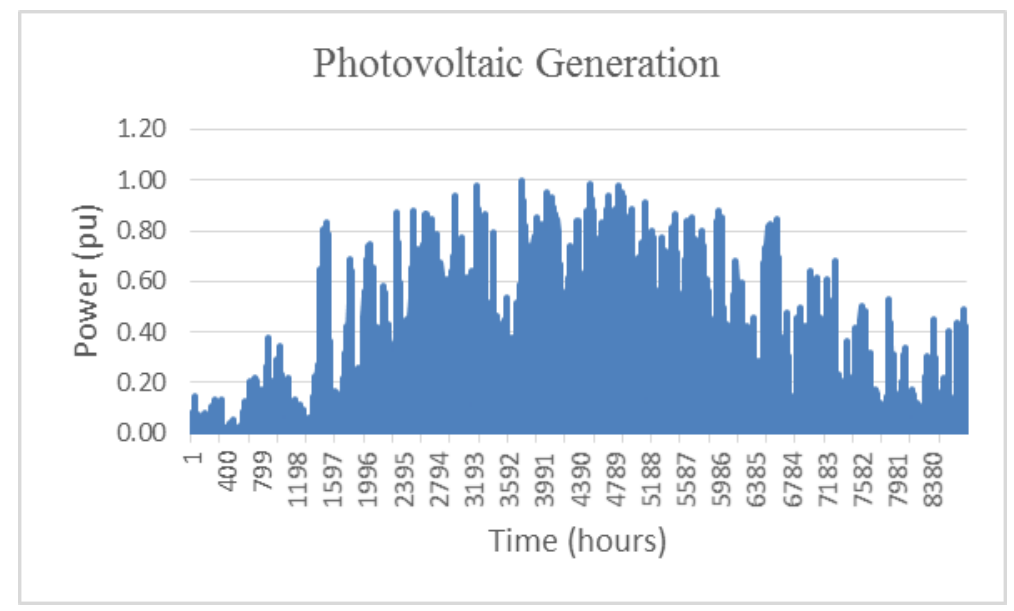

Figure 7. PV generation. Data corresponding to Germany- 50 Hertz (2013).

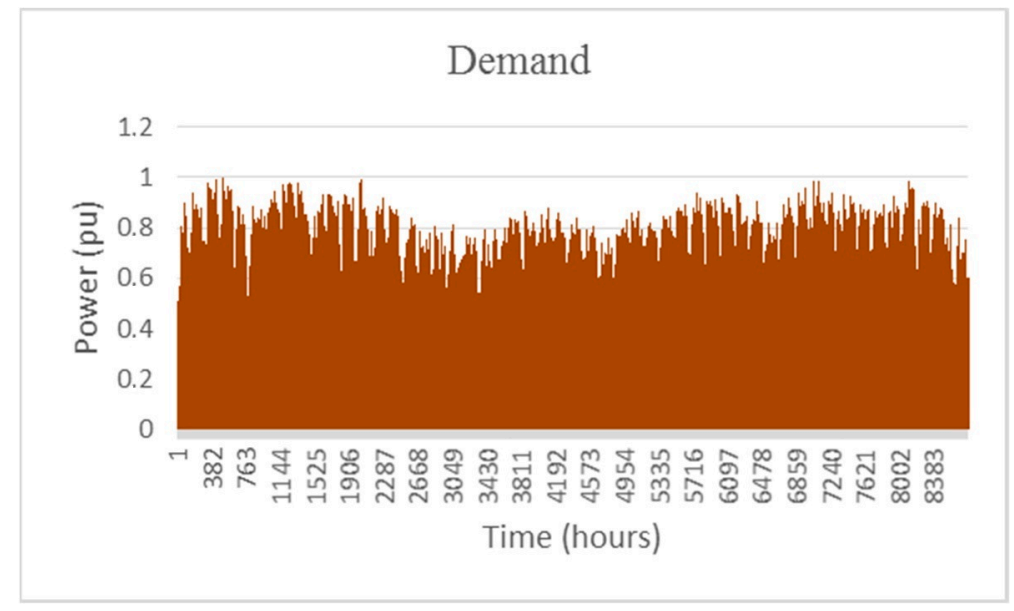

Figure 8. Demand data corresponding to Germany- 50 Hertz (2013).

In order to apply the method previously described in Section 2, these data are transformed into their corresponding $\mathrm{ODC}_{\mathrm{PV}}$ and LDC. In order to estimate the limit of $\mathrm{CD}_{\mathrm{PV}}$, the ratio between $\mathrm{t}_{\mathrm{vm}}$ and $t_{\mathrm{p}-\mathrm{a}}$ shown in Equation (10) will be considered. However, any other quotient in this equation can be also used.

\section{Results and Discussion}

Figure 9 shows the ODC $_{\mathrm{PV}}$ (blue shaded area) and LDC (red shading area) curves of these six large electricity grids, as well as the estimated value of the $\mathrm{CD}_{\mathrm{PV}}$ for each one. The axes in all graphs are normalized to the annual maximum value, in both power and time. It must be highlighted that the first four networks (a-d) represent the average year obtained between 2012 and 2103, both for photovoltaic and for demand, while the in the last two ones (e-f) the data only corresponds to 2013, the only year available. 
(a)

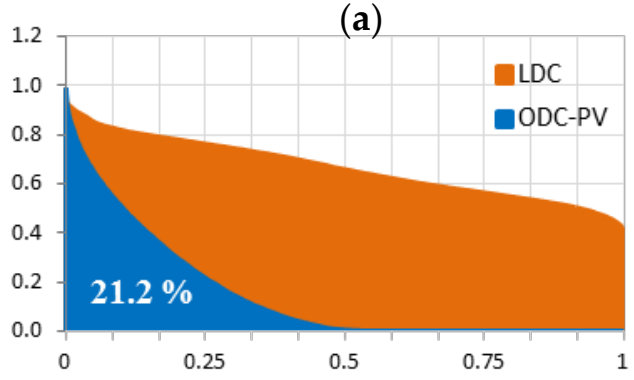

(c)

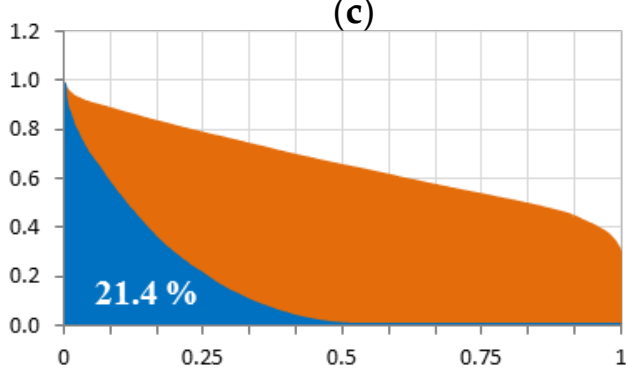

(e)

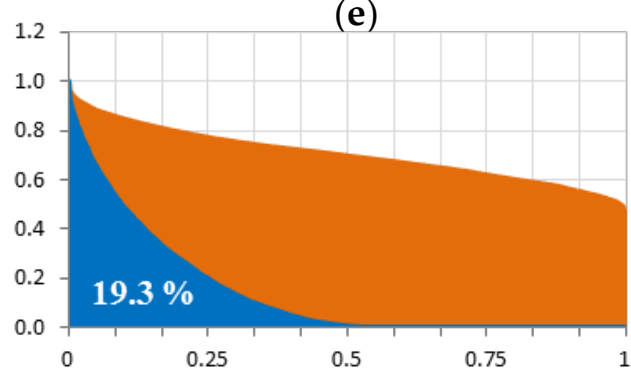

(b)

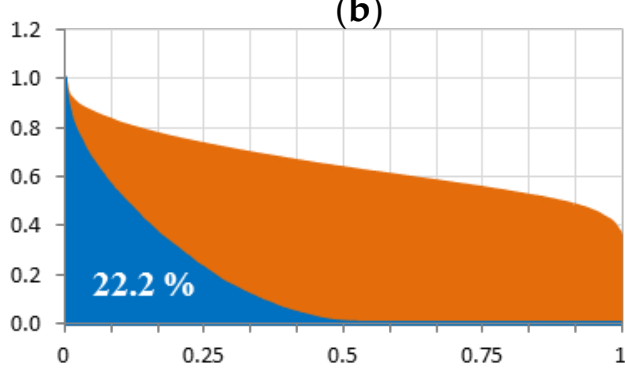

(d)

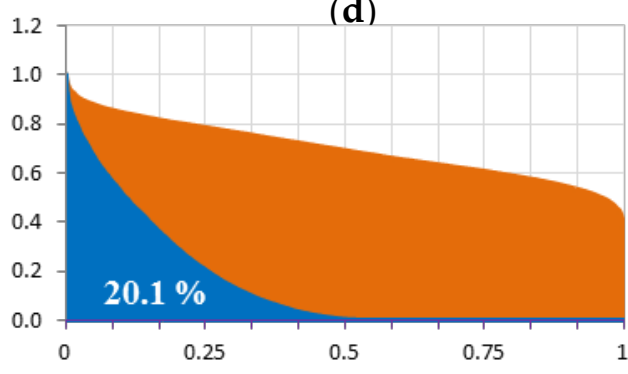

$(\mathbf{f})$

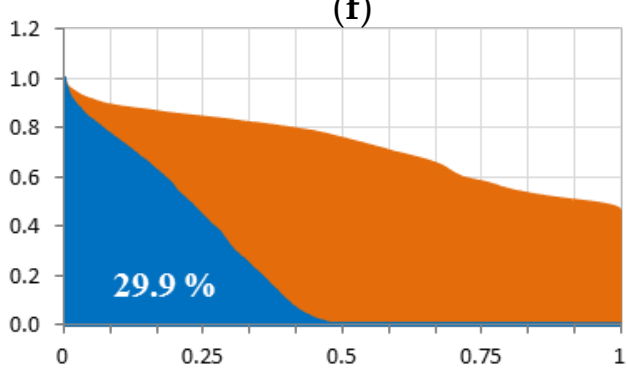

Figure 9. Limit of the CDPV for six european large electricity grids: (a) Amprion (Germany), (b) Tennet (Germany), (c) Transnet (Germany), (d) 50 Hertz (Germany), (e) Elia (Belgium) and (f) REE-Tenerife (Spain, Canary Islands).

Figure 9 is completed with the data shown in Table 2 which includes $t_{v m}, t_{p-a}$ and $C D_{P V}$ values for the six large electricity grids studied. In those grids where it has been possible to study more than one year, the average value of the studied years has been also included. As can be seen in this Table, $\mathrm{CD}_{\mathrm{PV}}$ varies between $19.3 \%$ and $19.5 \%$ for Elia (Belgium) and 50 Hertz (Germany), respectively, and the maximum value, 29\%, is reached by REE-Tenerife (Spain). All these values correspond to 2013 and they have been determined under the conditions given in Section 2.

In the case of REE-Tenerife, it can be seen that both the $t_{v m}$ and $t_{p-a}$ are the highest ones of the networks considered. Moreover, and as it has been aforementioned this electricity grid also provides the maximum $\mathrm{CD}_{\mathrm{PV}}$ of all the networks studied. This is clearly due to $t_{\mathrm{vm}}$, which is approximately $50 \%$ higher than the other central European electricity grids (this is due to its climatology and its geographical location which is very close to the Tropic of Cancer) while its $t_{p-a}$ is only slightly higher. Whereas, the minimum values obtained in Elia and 50 Hertz networks are due to both a decrease in their $t_{v m}$ and a high level of $t_{\text {p-a }}$.

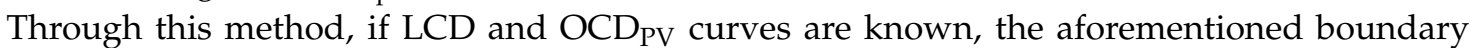
conditions are set and using Equation (10), the $\mathrm{CD}_{\text {PVMAX }}$ in a given network can be determined only knowing four parameters of the electricity grid: annual energy and maximum annual power, both for demand and for PV generation. This fact may be of interest when analysing networks that have the same LCD and ODC ${ }_{P V}$ profiles. If these curves are not available, the method shown in Figure 2 will have to be applied, i.e., firstly it should be obtained $L C D$ and $O D C_{P V}$ curves for that network should be obtained. Moreover, this method has the advantage of obtaining an upper limit in the $C_{P V}$ 
in a simple and intuitive way, which is stable for a given electricity grid and for different years. The knowledge of this limit may be of special interest for the energy planning of a territory and for the management of the electricity grids operators.

It must be highlighted that the values obtained by this method may differ from those that would be obtained by the methods presented in Section 1 as it eliminates the random and the periodic variability of the power both demand and generation.

Table 2. $\mathrm{CD}_{\mathrm{PV}}$ estimation for several European large electricity grids.

\begin{tabular}{ccccc}
\hline Electricity Grid & Year & $\begin{array}{c}\mathbf{t}_{\mathbf{v m}} \\
\text { (hours) }\end{array}$ & $\begin{array}{c}\mathbf{t}_{\mathbf{p}-\mathbf{a}} \\
\text { (hours) }\end{array}$ & $\begin{array}{c}\text { CD } \\
\text { (\%) }\end{array}$ \\
\hline \multirow{3}{*}{ Amprion } & 2012 & 1240 & 5630 & 22 \\
& 2013 & 1217 & 5972 & 20.4 \\
& Average & 1228 & 5801 & 21.2 \\
\hline Tennet & 2012 & 1257 & 5774 & 21.8 \\
& 2013 & 1243 & 5481 & 22.7 \\
& Average & 1250 & 5623 & 22.2 \\
\hline Transnet & 2012 & 1202 & 5332 & 22.5 \\
& 2013 & 1245 & 6101 & 20.4 \\
& Average & 1223 & 5717 & 21.4 \\
\hline 50 Hertz & 2012 & 1289 & 6106 & 20.8 \\
& 2013 & 1178 & 6043 & 19.5 \\
& Average & 1223 & 6075 & 20.1 \\
\hline Elia & 2013 & 1185 & 6134 & 19.3 \\
REE-Tenerife & 2013 & 1877 & 6282 & 29.9 \\
\hline
\end{tabular}

\section{Conclusions}

In this paper a new method has been developed to estimate the limit of the $C D_{\mathrm{PV}}$ in large electricity grids. Solar PV has a limitation when considering the amount of energy that can be absorbed by a large conventional electrical network. This is due to the matching between the demand curve and the photovoltaic generation curves. Currently, in most networks, the installed photovoltaic power is far from reaching this limit. However, the accumulated PV power is continuously increasing and may get closer to this limit in the next decades. The $\mathrm{CD}_{\text {PVMAX }}$ may provide, given the aforementioned boundary conditions, the maximum photovoltaic power that a given network can absorb if neither storage nor inter-network exchanges are considered.

The method has the advantage of eliminating the random and the periodic variability over time of the PV power and, to a lesser extent, the demand power. This is achieved through the $\mathrm{ODC}_{\mathrm{PV}}$ and the LDC curves which, together with the best scenario conditions to maximize the $\mathrm{CD}_{\mathrm{PV}}$, make it possible to obtain the theoretical limit which the PV generation can achieve for a given electricity grid. This limit depends both on the profiles of $\mathrm{LDC}$ and $\mathrm{ODC}_{\mathrm{PV}}$, both stable over time for an electricity grid.

The CDPvMAx constitutes a theoretical limit that shows the potential of this technology and the ability of PVs to cover the electricity demand for a given grid. Values beyond this limit are not possible if no electrical storage and photovoltaic overgeneration are considered. For this reason, to know this limit can be very useful in energy planning of large electricity grids as it provides certainty to future projects of photovoltaic installations about the capacity of the demand to absorb the photovoltaic energy that can be generated. It can be very useful in energy planning of large electricity grids as it provides certainty to future projects of photovoltaic installations about the capacity of the demand to absorb the photovoltaic energy that can be generated. It must be stated that the limit developed in the manuscript provides the potential of PVs alone when facing the demand.

In order to illustrate the method, the latter has been applied to several electricity grids. For the analysed grids, this limit in the $\mathrm{CD}_{\mathrm{PV}}$ moves between $19.3 \%$ and $29.9 \%$ of the annual energy demand 
in the corresponding electricity grid. It should be noted that these values are determined without storage, without PV generation overcapacity and with the conventional $\mathrm{ODC}_{\mathrm{PV}}$ and LDC profiles of each network. This limit is not universal but depends on the LDC and the $\mathrm{ODC}_{\mathrm{PV}}$ of each grid.

In addition, this limit can be increased by means of improvements in PV generation, such as the incorporation of the geographic dispersion between PV plants, solar tracking, PV overcapacity and the storage of photovoltaic generation surplus. Furthermore, by managing the electricity demand, this limit can be also increased, e.g.: if the peak of daily demand shifts towards solar noon and the peak of annual demand towards the summer solstice, the valley of daily demand during the night or increases demand on weekends and holidays. Future works should be developed in this sense in order to know the effect of the aforementioned factors when determining the limit on the coverage of the demand by photovoltaics.

The practical limit of the $\mathrm{CD}_{\mathrm{PV}}$ that can be reached in conditions of network security, guarantee of supply and competitive costs depends on multiple factors that are beyond the scope of this work.

Author Contributions: Conceptualization, F.B., P.G.V. and G.A.; methodology, F.B., F.J.M.-R. and G.A. software, F.B.; validation, F.B. and G.A.; formal analysis, F.B., F.J.M.-R. and P.G.V.; investigation, F.B., G.A. and P.G.V.; resources, F.B.; data curation, F.B.; writing-original draft preparation, F.B. and F.J.M.-R.; writing-review and editing, F.B. and F.J.M.-R.; visualization, F.B. and F.J.M.-R.; supervision, G.A. and P.G.V.; project administration, P.G.V.; funding acquisition, G.A. All authors have read and agreed to the published version of the manuscript.

Funding: This research was partially funded by Agencia Estatal de Investigación (AEI) and the Fondo Europeo de Desarrollo Regional (FEDER) aimed at the Challenges of Society, grant number ENE 2017-83860-R "Nuevos servicios de red para microredes renovables inteligentes. Contribución a la generación distribuida residencial".

Acknowledgments: The authors want to thank the reviewers for the interesting and valuable suggestions made.

Conflicts of Interest: The authors declare no conflict of interest.

\section{Abbreviations}

\begin{tabular}{|c|c|c|}
\hline \multicolumn{3}{|l|}{ Symbology } \\
\hline Symbol & Description & Units \\
\hline $\mathrm{C}_{\text {Mag }}$ & Coefficient that provides the matching in magnitude between the PV and demand. & - \\
\hline $\mathrm{C}_{\mathrm{T}}$ & $\begin{array}{l}\text { Coefficient that provides the matching between the annual PV generation time and the } \\
\text { demand annual time }\end{array}$ & - \\
\hline $\mathrm{E}_{\text {matchDPV }}$ & $\begin{array}{l}\text { Amount of photovoltaic energy that can be injected into the power grids and be } \\
\text { absorbed by the demand (matched energy between Demand and PV generation) }\end{array}$ & Wh/year \\
\hline$E_{\text {Dem }}$ & Demand Energy from power grid & Wh/year \\
\hline $\mathrm{E}_{\mathrm{PV}}$ & Photovoltaic energy injected to power grid & Wh/year \\
\hline$P_{\max -a}$ & Maximun annual hourly power & W \\
\hline $\mathrm{P}^{\mathrm{Dem}}$ max-a & Maximun annual hourly power demanded & W \\
\hline $\mathrm{P}^{\mathrm{PV}(\mathrm{AC})}{ }_{\text {max-a }}$ & Maximun annual hourly AC power generated for PV & $\mathrm{W}$ \\
\hline$P_{\text {avg-a }}$ & Average hourly annual power & W \\
\hline$P_{\text {avg(tg-a) }}$ & Average annual generated Power & W \\
\hline $\mathrm{P}^{\mathrm{Dem}}{ }_{\mathrm{ni}}$ & Average demand power for sample i & $\mathrm{W}$ \\
\hline $\mathrm{P}^{\mathrm{PV}}{ }_{\mathrm{ni}}$ & Average generated powwer for sample i & $\mathrm{W}$ \\
\hline $\mathrm{P}_{\mathrm{pu}}$ & Per-unit power & $\mathrm{pu}$ \\
\hline$t_{g-a}$ & Annual photovoltiac generation time & hours \\
\hline$t_{\max -\mathrm{a}}$ & Maximun annual time & hours \\
\hline$t_{\mathrm{p}-\mathrm{a}}$ & Equivalent annual time at maximun annual demand power & hours \\
\hline$t_{\mathrm{vm}}$ & Equivalent annual time at maximum annual generated power & hours \\
\hline Wh & Watts-hour & $3.6 \times 10^{3} \mathrm{~J}$ \\
\hline W & Watts & \\
\hline$\Delta \mathrm{t}$ & Recording interval & hour \\
\hline \multicolumn{3}{|l|}{ Acronyms } \\
\hline MAtchDPV & Matching between demand and photvoltaic generation & \\
\hline $\mathrm{CD}_{\mathrm{PV}}$ & Coverage of Demand by photovoltaics & \\
\hline $\mathrm{CF}$ & Capacity Factor & \\
\hline
\end{tabular}




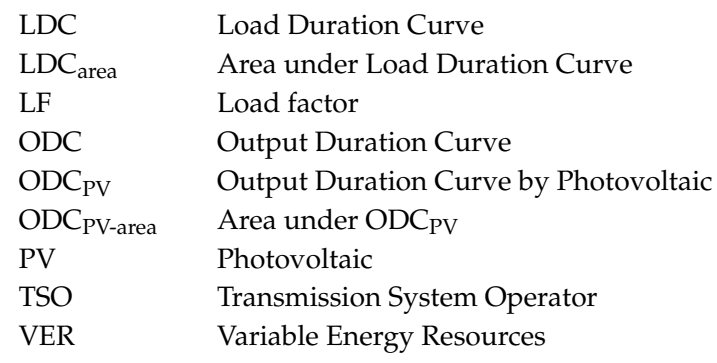

\section{References}

1. Massachusetts Institute of Technology (MIT). Chapter 3: Integration of Variable Energy Resources. In The Future of the Electric Grid: An Interdisciplinary MIT Study; MIT: Cambridge, MA, USA, 2011; pp. 53-71.

2. European Photovoltaic Industry Association (EPIA). Conecting the Sun: Solar Photovoltaic on the Road to Large-Scale Grid Integration; EPIA: Brussels, Belgium, 2012.

3. Gyalai-Korpos, M.; Zentkó, L.; Hegyfalvi, C.; Detzky, G.; Tildy, P.; Baranyai, N.H.; Pintér, G.; Zsiborács, H. The Role of Electricity Balancing and Storage: Developing Input Parameters for the European Calculator for Concept Modeling. Sustainability 2020, 12, 811. [CrossRef]

4. Mills, A.; Ahlstrom, M.; Brower, M.; Ellis, A.; George, R.; Hoff, T.; Wan, Y.-H. Understanding Variability and Uncertainty of Photovoltaics for Integration with the Electric Power System. Available online: https: //emp.lbl.gov/sites/all/files/lbnl-2855e.pdf (accessed on 2 May 2020).

5. Gönen, T. Electric Power Distribution Engineering, 3rd ed.; CRC Press/Taylor\& Francis Group: Boca Raton, FL, USA, 2014.

6. Baena Villodres, F. Influence of Photovoltaic Electricity on the Energy Mix. Theoretical Limit in Coverage for Electricity Demand by Solar Photovoltaic Energy. Ph.D. Thesis, University of Jaén, Jaén, Spain, 2017.

7. Súri, M.; Huld, T.A.; Dunlop, E.D.; Ossenbrink, H.A. Potencial of solar electicity generation in the European Union member states and candidate countries. Sol. Energy 2007, 81, 1295-1305. [CrossRef]

8. Eltawil, M.A.; Zho, Z. Grid-connected photovoltaic power systems: Technical and potential problems. A review. Renew. Sustain. Energy Rev. 2010, 14, 112-129. [CrossRef]

9. Ceccaroli, B.; Lohe, O. Solar grade silicon feedstock. Chapter 5. In Handbook of Photovoltaic Science and Engineering, 2nd ed.; Luque, A., Hegedus, S., Eds.; Wiley \& Sons: Hoboken, NJ, USA, 2010.

10. Braun, M.; Stetz, T.; Bründlinguer, R.; Mayr, C.; Ogimoto, K.; Hatta, H.; MacGill, I. Is the distribution grid ready to accept large-scale photovoltaic deployment? State of the art, progress and future prospects. Prog. Photovolt. Res. Appl. 2012, 20, 681-697. [CrossRef]

11. IEA PVPS. PVPS Report: A Snapshot of Global PV 1992-2015; Report: IEA PVPS T1-29:2016; IEA: Paris, France, 2016.

12. IEA PVPS. Snapshot of Global Photovoltaic Markets 2020; Report IEA PVPS T1-37:2020; IEA: Paris, France, 2020.

13. Solar Power Europe. Global Market Outlook For Solar Power/2020-2024; Solar Power Europe: Brussels, Belgium, 2020.

14. Denholm, P.; Margolis, R.M. Evaluating the limits of solar photovoltaics (PV) in traditional electric power system. Energy Policy 2007, 35, 2852-2861. [CrossRef]

15. Denholm, P.; Margolis, R. Evaluating the limits of solar photovoltaics (PV) in traditional electric power systems utilizing energy store and other enabling technologies. Energy Policy 2007, 35, 4424-4433. [CrossRef]

16. Nikolakis, T.; Fthenakis, V. The optimum mix of electricity from wind- and solar- sources in conventional power systems: Evaluating the case for New York State. Energy Policy 2011, 39, 6972-6980. [CrossRef]

17. Baumgartner, F.; Achtnich, T.; Remund, J.; Gnos, S.; Nowak, S. Steps towards integration of PV-electricity into the Grid. Prog. Photovolt. Res. Appl. 2011, 19, 834-843. [CrossRef]

18. Häberlin, H. Photovoltaics: System Design and Practice; John Wiley \& Sons: Hoboken, NJ, USA, 2012.

19. Masters, G.M. Renewable and Efficient Electric Power Systems; John Wiley \& Sons: Hoboken, NJ, USA, 2004.

20. Baena, F.; Terrados, J.; Gómez-Bueno, P.; Almonacid, G.; Vidal, P.; Valera, P.; Almonacid, L. Output Duration Curve. An Useful Tool for PV Analysis and Grid Integration. European PV Solar Energy Conference and Exhibition. In Proceedings of the EU PVSEC2015, Hamburg, Germany, 14-18 September 2015; pp. 3104-3108. 
21. Poulin, A.; Dostie, M.; Fournier, M.; Sansregret, S. Load Duration Curve: A Tool for Technico-Economic Analysis of Energy Solutions. Energy Build. 2008, 40, 29-35. [CrossRef]

22. Wiskich, A. Implementing a Load Duration Curve of Electricity Demand in a General Equilibrium Model. Energy Econ. 2014, 45, 373-380. [CrossRef]

23. Soyster, A.; Eynon, R. The conceptual basis of the Electric Utility Sub-Model of Project Independence Evaluation System. Appl. Math. Model. 1979, 3, 242-248. [CrossRef]

24. European Committee for Electrotechnical Standardization. IEC 61724: Photovoltaic System Performance Monitoring; IEC: Brussels, Belgium, 2017.

25. Bobmann, T.; Staffell, I. The shape of future electricity demand: Exploring load curves in 2050s Germany and Britain. Energy 2015, 90, 1317-1333.

26. 50hertzPV. Available online: http://www.50hertz.com/en/Grid-Data/Photovoltaics/Archive-Photovoltaics (accessed on 10 May 2015).

27. Tennet PV. Available online: http://www.tennettso.de (accessed on 14 May 2015).

28. Amprion PV. Available online: http://www.amprion.net/en/photovoltaic-infeed (accessed on 22 May 2015).

29. TransnetBW PV. Available online: http://www.transnetbw.de/en/key-figures/renewable-energies/photovoltaic (accessed on 24 April 2015).

30. Elia PV. Available online: http://www.elia.be/en/grid-data/power-generation/Solar-power-generation-data/ Graph (accessed on 15 February 2015).

31. REE. Canary System PV. Available online: https://www.ree.es/es/actividades/sistema-electrico-canario (accessed on 24 December 2015).

32. 50hertz. Available online: http://www.50hertz.com/en/ (accessed on 10 May 2015).

33. Amprion. Available online: http://www.amprion.net/en (accessed on 12 March 2015).

34. TransnetBW. Available online: https://www.transnetbw.com (accessed on 14 December 2014).

35. Tennet. Available online: http://www.tennettso.de/site/en/ (accessed on 14 January 2014).

36. Elia. Available online: http://www.elia.be/en/grid-data/Load-and-Load-Forecasts/total-load (accessed on 20 December 2014).

37. REE. Red Eléctrica de España. Available online: http://www.ree.es/es/actividades/sistema-electrico-canario/ demanda-de-energia-en-tiempo-real (accessed on 20 March 2015).

38. Official Journal of the European Union. Commission Regulation (EU) No 543/2013 of 14 June 2013 on submission and publication of data in electricity markets and amending Annex I to Regulation (EC) No 714/2009 of the European Parliament and of the Council. 2013. Available online: http://data.europa.eu/eli/ reg/2013/543/oj (accessed on 14 May 2020).

39. Heizer, J.; Render, B. Operations Management, 9th ed.; Prentice Hall: Upper Saddle River, NJ, USA, 2007.

40. European Union. Directive 2000/84/EC of the European Parliament and of the Council of 19 January 2001 on Summer-Time Arrangements. 2015. Available online: http://data.europa.eu/eli/dir/2000/84/oj (accessed on 14 May 2020).

(C) 2020 by the authors. Licensee MDPI, Basel, Switzerland. This article is an open access article distributed under the terms and conditions of the Creative Commons Attribution (CC BY) license (http://creativecommons.org/licenses/by/4.0/). 